\title{
A pesquisa de intervenção na psicologia da educação matemática: aspectos conceituais e metodológicos ${ }^{1}$
}

\section{Intervention research in the psychology of mathematics education: conceptual and methodological aspects}

\author{
Maria Helena Fávero²
}

\begin{abstract}
RESUMO
Focamos um dos grandes desafios atuais da psicologia: a pesquisa de intervenção tomada como geradora de transformação e que, ao mesmo tempo, evidencia o processo a ela subjacente. Expomos nossa linha teóricometodológica de investigação e relatamos uma pesquisa de intervenção no contexto da psicologia da educação matemática. Consideramos quatro aspectos teórico-conceituais articulados: 1 . a evidência das interações entre as regulações cognitivas e as sociais; 2. o papel da mediação semiótica no desenvolvimento psicológico humano; 3 . os efeitos dos sistemas de signos no desenvolvimento psicológico e nas comunicações individuais; 4. a tomada de consciência de que as ações humanas não são aleatórias: trata-se de práticas sociais com um conteúdo que lhes dão fundamento. Tais aspectos fundamentam a Psicologia do conhecimento e o método adotado, com um duplo desafio: desenvolver um procedimento visando à tomada de consciência de uma professora licenciada em matemática sobre o paradigma que sustentava sua prática e o reformulasse assumindo um trabalho sistematizado de articulação entre intervenção psicopedagógica e pesquisa, que possibilitasse: 1 . o estudo das aquisições conceituais dos alu-
\end{abstract}

1 Trabalho desenvolvido no contexto do Projeto de Pesquisa - A construção de competências na escola: problematizando as situações matemáticas em sala de aula-Projeto de Pesquisa CNPq (Conselho nacional de desenvolvimento científico e tecnológico), Proc. 305305/2003-4 Modalidade: PQ.

2 Professora doutora do Departamento de Psicologia Escolar e do Desenvolvimento e do Programa de Pós-Graduação em Processos de Desenvolvimento Humano e Saúde $(<\mathrm{http}: / /$ www. pedpos.ip.unb.br/>), coordenadora do Cogito - Laboratório de Psicologia do Conhecimento, Instituto de Psicologia da Universidade de Brasília (UnB), Brasília, Brasil. (faveromh@unb.br). 
nos; e 2. a análise dos processos mediacionais das interações interpessoais, considerando a natureza do material utilizado e das atividades propostas. Os resultados evidenciaram a pertinência do procedimento: as atividades propostas e a qualidade da atividade mediada engendraram a aquisição de novas competências conceituais nos alunos e o desenvolvimento de novas competências para a professora como mediadora do conhecimento. Palavras-chave: pesquisa de intervenção; psicologia do conhecimento; psicologia da educação matemática; tomada de consciência; atividade mediada.

\begin{abstract}
We focus on one of the great current challenges in psychology: interventional research aimed at generating transformation while demonstrating its underlying process. We detail our theoretical and methodological approach and describe an interventional study in the psychology of mathematics education. The psychology of knowledge and our method are based on four connected theoretical aspects: 1 . the evidence of interaction between cognitive and social regulations; 2 . the role of semiotic mediation in human psychological development; 3 . the effects of sign systems on psychological development and individual communication; 4. the realisation that human actions are not at random, but rather content-based social practices. The study involved a double challenge: to develop a procedure to bring a mathematics teacher to a grasp of consciousness regarding the paradigm underpinning her practice, and to reformulate it on the basis of a deliberate articulation between psycho-pedagogical intervention and research, allowing us to: 1 . study the students' conceptual acquisitions, and 2. analyse the mediation processes involved in the interpersonal relations, taking into account the nature of the material utilised and the activities proposed. The activities proposed and the quality of the mediated activity meant that students acquired new conceptual competence and the teacher developed new competence as a knowledge mediator.

Keywords: interventional research; psychology of knowledge; psychology of mathematics education; grasp of consciousness; mediated activity.
\end{abstract}




\section{Introdução}

Um dos grandes desafios atuais da pesquisa psicológica é a pesquisa de intervenção tomada no sentido da pesquisa que gera transformação e ao mesmo tempo obtém dados do processo subjacente a ela. Quando se trata da pesquisa de intervenção no meio escolar, temos considerado três questões-chave, fundamentadas em anos de pesquisas centradas nas questões relacionadas às competências conceituais das áreas do conhecimento, assim como no desenvolvimento das competências particulares de futuros professores, professores em atuação e outros profissionais da educação. A primeira questão diz respeito à concepção sobre ciência: ainda é comum se pensar que "ciência" - ciências exatas, ciências naturais, ciências humanas e ciências sociais - e "filosofia" constituem duas atividades separadas. A segunda é que essa ruptura fundamenta uma concepção de ciência como um conjunto de conhecimentos separados em áreas diferentes, o que fundamenta, por sua vez, a ideia equivocada de uma ciência pronta e acabada e que como tal deve ser repassada aos estudantes. A terceira é que tais representações fundamentam uma prática de ensino na qual a memorização de regras tem primazia sobre a compreensão conceitual, o que dificulta o desenvolvimento de competências conceituais e o desenvolvimento do pensamento crítico em relação ao próprio conhecimento (FÁVERO, 2009).

Em nossa atividade como pesquisadora, docente e orientadora, temos procurado fundamentar um aporte teórico e metodológico para intervir nessas questões-chave, o que pressupõe tanto a consideração da filosofia e da epistemologia da construção dos saberes particulares, como dos processos psicológicos desenvolvimentais que sustentam essa construção (FÁVERO, 2000; 2007; SOUZA; FÁVERO, 2002; FÁVERO; COUTO MACHADO, 2003; FÁVERO; VIEIRA, 2004; FÁVERO; PIMENTA, 2006; NEVES; FÁVERO, 2009, por exemplo). Nosso intuito tem sido o de estabelecer uma articulação entre a psicologia e o conhecimento e fundamentar a psicologia do conhecimento (FÁVERO, 2005a; 2005b; 2009).

Neste texto temos dois objetivos: expor nossa linha teórico-metodológica de investigação para a intervenção e relatar uma pesquisa de intervenção no contexto da psicologia da educação matemática, desenvolvida com uma professora e seus alunos.

O aporte teórico-conceitual e metodológico que a sustentou é aquele que temos defendido já há uma década: um aporte que se fundamenta na articulação e no consenso dos grandes teóricos da psicologia, tais como Piaget (1977), Wallon (1963) e Vygotsky (1979), assim como nos grandes pensadores como 
George Mead (1992), Bakhtin (1981), Geertz (1989) e Lotman (1990), e dos pensadores contemporâneos como Bourdieu (1982), Bruner (1990) e Moscovici (1986) (ver: FÁVERO, 2005a; 2005b; 2009).

Trata-se, portanto, de uma postura inter e multidisciplinar que fundamenta a seguinte tese: o ser humano se desenvolve através da construção dialética da interação e adaptação com o meio sociocultural, sustentada pelos processos de internalização e externalização que engendram a tomada de consciência e para os quais os sistemas de signos são especialmente importantes, já que se trata de lidar com a representação (FÁVERO, 2005a; 2009).

Essa tese implica a consideração de pelo menos quatro aspectos teóricoconceituais articulados: 1. A evidência das interações entre as regulações cognitivas e as regulações sociais; 2 . O papel da mediação semiótica nos processos de desenvolvimento psicológico humano; 3 . Os efeitos dos sistemas de signos no desenvolvimento psicológico e na cognição das comunicações individuais e os modos como as práticas das instituições sociais interagem com o funcionamento mental do indivíduo; 4 . A tomada de consciência de que as ações humanas não são aleatórias; ao contrário, trata-se de práticas sociais com um conteúdo que lhes dão fundamento. Por meio desse referencial teórico temos fundamentado a Psicologia do conhecimento (FÁVERO, 2009).

Considerar esse aporte na prática da pesquisa e na prática de ensino implica admitir ambos: que a atividade no processo ensino-aprendizagem é mediada e que, embora considerando a dinâmica sociocognitiva, devemos considerar as construções cognitivas elaboradas e exploradas por cada indivíduo na situação. Assim, temos procurado defender a importância da autorregulação no funcionamento cognitivo de cada sujeito no contexto interacional (FÁVERO, 2000).

Compatível com essas considerações, temos defendido uma articulação teórico-metodológica que considera três aportes particulares: a situação interacional, a análise dos atos da fala e a tomada de consciência no sentido desenvolvimental piagetiano. Adotar a análise dos atos da fala produzidos na interação significa defender um procedimento que, ao mesmo tempo, evidencia a tomada de consciência de cada sujeito e evidencia seus processos de regulações cognitivas e metacognitivas, por meio da análise dos processos comunicacionais das interações (FÁVERO, 2005b).

Trazendo esse aporte teórico-metodológico para a pesquisa de intervenção no contexto da Psicologia da educação matemática, duas considerações devem ser salientadas. A primeira diz respeito à utilização de situações problemas como instrumento de mediação do conhecimento, em uma situação de interação social particular. A segunda diz respeito à relação dialética entre a aquisição conceitual e a capacidade de resolução de problemas, no sentido que Piaget atribuiu ao conceito de abstração reflexiva. Ambas são válidas para os nossos dois focos: 
o desenvolvimento das competências dos alunos e o desenvolvimento das competências do adulto que é o professor.

Por isso, um trabalho que visa o desenvolvimento de novas competências no professor deve considerar o aporte da Psicologia do desenvolvimento adulto, que, compatível com nossa abordagem conceitual, tem sido considerada nos últimos 20 anos como uma fase caracterizada pela união do cognitivo e do afetivo, do self e do outro e da ideia com a ideia (KEGAN, 1994; SINNOTT, 1998; YOUNG, 1997): “[...] o adulto é visto como um construtor ativo de verdades múltiplas, polissêmicas e utilitárias, o que significa estar em desenvolvimento em um universo do desenvolvimento do modo coletivo de pensar" (FÁVERO; COUTO MACHADO, 2003, p. 18).

A referência à polissemia diz respeito à perspectiva defendida por Bakhtin (1981) e entende a construção de significados como produto das relações do contexto cultural e de criações individuais, na mesma linha de raciocínio que já expusemos antes. Assim, a intervenção que visa mudanças na prática do professor implica um processo de reconstrução polissêmica, pois não é só o campo conceitual das áreas de conhecimento específico que está em jogo (da matemática, por exemplo), mas o modo como se concebe a sua interação com o próprio desenvolvimento humano e as representações sociais que a elas estão vinculadas.

Portanto, a questão das competências referentes à prática de ensino diz respeito a uma criação particular e complexa: reformular a prática de ensino pressupõe uma construção e o que temos defendido é que essa se viabiliza fundamentada em dois processos: primeiro, na tomada de consciência do professor, dos significados que sustentam sua prática e das implicações que dela decorrem e, segundo, na tomada de consciência da existência de outros modos de refletir sobre ela (FÁVERO, 2000; 2007). Este aporte é compatível com a tendência das publicações internacionais dessa última década: entende o professor como um construtor (EBBY, 2000); toma o construtivismo não apenas como uma teoria da aprendizagem, mas o considera também nas condições de intervenção visando o desenvolvimento do professor (GOODELL, 2006); considera os processos construtivos individuais na resolução das perturbações advindas da reflexão sobre suas próprias ações (LEE, 2005). Ele também é compatível com a perspectiva de Sinnott (1998), uma vez que defendemos o reconhecimento de que: o desenvolvimento psicológico continua na vida adulta; a importância das experiências pessoais, subjetivas e particulares, que demandam que uma pessoa adulta considere múltiplas perspectivas, tais como a negociação dos relacionamentos e conflitos e a existência de uma lógica pós-formal, própria do pensamento adulto que lhe permite tomar decisões sobre qual sistema lógico formal utilizar em uma dada interação epistemológica com a realidade, seja essa 
realidade de cunho científico, interpessoal ou de outra natureza.

Esse foi o aporte teórico-metodológico que fundamentou o estudo que relatamos a seguir: tratava-se de considerar o fundamento epistemológico da tese da inclusão educacional, o papel da sala de recursos nesta tese e a prática psicopedagógica como atividade para o desenvolvimento deste papel.

\section{O método}

Participaram deste trabalho, uma professora licenciada há 8 anos em matemática e que atuava na sala de recursos de uma Escola da Rede Pública de Ensino do Distrito Federal; quatro alunos, dois do sexo masculino e dois do feminino, entre 14 e 19 anos, em processo de inclusão na 5. ${ }^{a}$ série do Ensino Fundamental, que frequentavam a sala de recursos em horário contrário às aulas. Suas professoras os haviam apontado como alunos "com problemas de aprendizagem em matemática, sobretudo nas operações aritméticas". Todos eles haviam sido diagnosticados, pela Equipe de Avaliação Psicopedagógica da Secretaria de Estado de Educação do Distrito Federal (SEE/DF), como portadores de deficiência mental.

O procedimento adotado nas sessões de intervenção foi fundamentado na mediação da reconstrução individual dos instrumentos culturais da aprendizagem e do pensamento, por meio da reestruturação das experiências pessoais, tanto da professora como dos alunos. Estava em questão, portanto, dois tipos de tutoramento: o tutoramento da professora pela pesquisadora e o tutoramento dos alunos pela professora.

Assim, o objetivo da nossa pesquisa de intervenção foi o desenvolvimento de competências específicas por parte da professora no que se refere à tomada de consciência do processo de construção da tese da inclusão e seus pressupostos, do seu papel como mediadora de conhecimento na sala de recursos, o que implicava em três tarefas: a avaliação psicopedagógica dos alunos, a proposta de atividades e análise do desenvolvimento dessas atividades e a proposta de novas atividades baseadas nessa análise. Isso foi desenvolvido por meio de quatro etapas registradas em áudio, transcritas e analisadas: 1. ${ }^{a}$ - leitura e discussão dos documentos relacionados à inclusão educacional (BRASIL/MEC, 1996; 2001a; 2001b; 2003); 2. ${ }^{\mathrm{a}}$ - avaliação individual das competências e dificuldades matemáticas dos alunos; 3 . $^{\mathrm{a}}$ - intervenção psicopedagógica junto aos alunos e em grupo, com sessões variando entre 40 e 55 minutos; e $4 .^{\text {a }}$ - avaliação individual dos alunos, pós-intervenção psicopedagógica. A 1. ${ }^{\mathrm{a}}$ e a 2. ${ }^{\mathrm{a}}$ fases foram 
concomitantes.

Na segunda fase - avaliação das competências e dificuldades matemáticas - considerando a ampla literatura sobre a construção do conceito de número - desde Piaget aos autores posteriores, como Resnick (1982), Carpenter e Moser (1983) e Vergnaud (1990), por exemplo - cada sujeito foi submetido, individualmente, a três provas diferentes: a Prova Conceitual de Resolução de Problemas Numéricos - ECPN (Groupe CIMETE, 1995)³ -, a Prova de Sequência Numérica e a uma prova em grupo, a Prova de Medidas, sendo que as duas últimas foram elaboradas após análise dos resultados obtidos na primeira. Portanto, não utilizamos testes padronizados, mas situações de avaliação psicopedagógica, tendo como foco o conceito de número e a lógica do sistema numérico decimal e sua notação.

A Prova de Sequência Numérica foi elaborada a partir de três situações distintas: uma com blocos lógicos, uma segunda com numerais emborrachados e uma terceira com a proposta de uma situação problema por escrito. Na primeira situação, o aluno era convidado a explorar, com a ajuda da professora, as características dos blocos lógicos de Diennes, visando sua utilização como critérios de ordenação. Em seguida, cinco diferentes sequências de blocos eram apresentadas, uma a uma, em ordem de dificuldade segundo o número de critérios (cor, espessura, tamanho e forma), solicitando-lhe que fosse dada uma continuidade. Na segunda situação esse procedimento foi repetido com os números emborrachados. Na terceira situação, em grupo, foi apresentado o seguinte problema digitado em uma folha de papel A4: Você viu nas Casas Bahia um Micro System no modelo que você há muito tempo tem sonhado em ter em uma promoção por $R \$ 364,50$. Essa promoção vai durar 15 dias. Você recebe um salário de $R \$ 600,00$ por mês. Então resolve economizar da seguinte maneira: $1^{\circ}$ dia, $R \$ 1,00 ; 2^{\circ}$ dia, $R \$ 2,00 ; 3^{\circ}$ dia, $R \$ 3,00 ; 4^{\circ}$ dia, $R \$ 5,00 ; 5^{\circ}$ dia, $R \$ 8,00 ; 6^{\circ}$ dia, $R \$ 13,00$ e assim por diante. Economizando desse modo, quantos dias você precisará economizar para ter o dinheiro suficiente para comprar o Micro System?

Portanto, a questão do problema referia-se ao tempo e não à quantia de dinheiro e sua resolução envolvia uma sequência numérica que deveria ser encontrada através da sua lei de formação, implicando, assim, o conceito de número e as relações do sistema decimal, incluindo as quatro operações. Após a resolução, a professora solicitava que cada sujeito lhe explicasse a maneira como havia resolvido o problema.

3 A Prova Conceitual de Resolução de Problemas Numéricos, a ECPN, foi proposta por pesquisadores franceses com o intuito de avaliar a aquisição do conceito de número e indicar como o sujeito constitui e utiliza as suas propriedades particulares. 
A Prova de Medidas constituiu-se de situações de comparação entre medidas de comprimento e de peso. Numa primeira etapa todos os sujeitos identificaram seus pesos na balança de uma farmácia nas vizinhanças da escola e, numa segunda, identificaram as suas alturas com uma fita métrica. Com os dados assim obtidos, a experimentadora e a professora elaboraram uma tabela com três colunas, uma para identificação de cada aluno, a segunda para os respectivos pesos e uma terceira para a altura. Tendo a tabela como fonte de dados, foram propostas ao grupo quatro questões sobre comparação dois a dois das medidas de massa e de comprimento e "n mais que".

A análise dos dados obtidos na avaliação individual das competências matemáticas dos alunos foi desenvolvida pela professora e pela experimentadora. Essa situação de análise gerou uma tomada de consciência por parte da professora e o desenvolvimento de competências particulares no que se refere aos significados das dificuldades e das competências dos alunos.

Em resumo, os dados obtidos na 2. ${ }^{\text {a }}$ fase evidenciaram que na prova ECPN (GROUPE CIMETE, 1995) os alunos se utilizaram da estimativa visual para comparar os conjuntos de elementos em questão, sem a quantificação numérica e tomando "n mais" como a designação da quantidade a ser acrescentada. Eles só apresentaram uma solução quando a professora interveio, igualando as coleções por meio da correspondência biunívoca, sem que tal procedimento tenha sido adotado pelos sujeitos nas situações problemas subsequentes. Na prova de sequência numérica, tanto com os blocos lógicos como com os números emborrachados, os alunos não demonstraram ter percebido a existência de um critério sequencial. Na prova de medidas, eles identificaram a parte inteira, porém, não identificaram os decimais (centímetros e gramas) e apesar de compararem as medidas duas a duas, não identificaram o "n mais". Compatível com tais dados, as respostas ao problema escrito não apresentaram uma solução; se obtiveram algumas tentativas que evidenciaram que os alunos conheciam algumas regras referentes aos algoritmos, mas que tais tentativas não tinham por base a lógica do sistema numérico e sua notação e seguiam um procedimento comum, isto é, a de operar, tomando os valores do enunciado do problema na mesma sequência em que apareciam.

Esses dados são compatíveis com outros estudos, como já amplamente descritos na literatura especializada e referidos desde os anos de 1980 como sendo erros baseados em regras, que derivam de procedimentos padronizados de resolução tal como ditados pelo meio escolar (ver: FÁVERO, 1999; FÁVERO; PIMENTA, 2006). 


\section{Resultados e discussão}

Os dados obtidos na avaliação psicopedagógica evidenciaram que o problema central dos alunos era a incompreensão da lógica do sistema numérico decimal, e consequentemente sua notação, o que lhes dificultava o manejo das operações. Portanto, a 3. ${ }^{a}$ fase do estudo teve como objetivo a mediação da mediação, isto é, a pesquisadora mediava a intervenção psicopedagógica desenvolvida pela professora que visava o tutoramento dos alunos na compreensão e elaboração da notação do sistema numérico.

Assim, propusemos à professora trabalhar com as medidas de comprimento, de tempo e monetária, privilegiando as situações problemas relacionadas à vida cotidiana e a utilização dos seus respectivos instrumentos, como a régua, o relógio, o calendário, as notas e as moedas de dinheiro, tomados como instrumentos mediadores para a elaboração de registros escritos. A experimentadora tutorava a professora para conduzir os alunos na checagem desses registros em relação aos princípios da lógica de notação do sistema numérico, de modo a promover "a reestruturação dos processos do pensamento e a reorientação da atenção do sujeito e dos procedimentos que ele empregava para chegar à solução do problema apresentado" (FÁVERO; SOARES, 2002, p. 46).

Onze (11) sessões de intervenção psicopedagógica foram desenvolvidas pela professora, sob o tutoramento da experimentadora. Isso significou levar a professora a desenvolver um trabalho sistemático: cada uma das sessões foi descrita em termos dos objetivos e das atividades propostas, foi registrada em áudio, transcrita na íntegra e avaliada em termos das competências e dificuldades de cada sujeito, especificando as sequências de suas ações, o seu significado em relação às aquisições de estruturas conceituais e o tipo de mediação estabelecida entre a professora e os alunos. Essa sistematização, no nosso entender, foi fundamental para que a professora tomasse consciência de que a sequência das sessões se definia na medida em que a análise de cada uma nos fornecia dados para o planejamento da seguinte. Como é inviável reproduzir aqui as onze transcrições, optamos por salientar os dados que consideramos mais relevantes.

A 1. a sessão foi desenvolvida tendo vários folhetos de publicidade de supermercados como material básico. A atividade proposta ao grupo era que cada aluno encolhesse nos folhetos o que gostaria de comprar considerando as condições de venda oferecidas e a compatibilidade com sua mesada. Os alunos apresentaram dificuldades no registro dos valores monetários e no respeito às condições. A análise da sequência das interlocuções evidenciou a tomada de consciência dos sujeitos em relação aos valores em questão, uma vez que mo- 
dificaram a escolha do objeto, de modo a diminuir, gradativamente, o valor a ser gasto na suposta compra e torná-lo viável com a mesada. Compatível com os dados da avaliação, os alunos apresentaram dificuldades com a lógica do sistema numérico e com sua notação. Assim, da 2. à 4. ${ }^{a}$ sessão, centrou-se na proposta de uma situação problema visando a operação com medidas monetárias e sua notação, utilizando-se, ainda, os folhetos de publicidade de supermercados. Diante da situação problema - Você viu em um folheto de supermercado um produto que gostaria de comprar. Você recebe uma mesada de $R \$ 50,00$. Se decidir não gastar nada da sua mesada, quanto tempo você precisaria para comprar o produto que você gostou? - todos os alunos armaram as operações de adição colocando unidades embaixo de unidades, dezenas embaixo de dezenas e centena embaixo de centena, efetuado-as da direita para a esquerda e de cima para baixo. No entanto, quase todos os resultados obtidos foram incorretos. Nenhum aluno fez uso da multiplicação e apenas dois deles fizeram uso da vírgula seguida dos 2 zeros para a representação do valor monetário.

Diante desses dados, foi elaborada uma sequência para a $5 .^{\mathrm{a}}$ sessão com o objetivo de mediar a interação dos alunos com os instrumentos de medida monetária, sua unidade e partes, utilizando-se notas e moedas de valores pequenos: 1. distribuição de $\mathrm{R} \$ 15,00$ para cada sujeito, sendo 1 nota de $\mathrm{R} \$ 5$, 00, 2 notas de $\mathrm{R} \$ 2,00,2$ notas de $\mathrm{R} \$ 1,00,3$ moedas de $\mathrm{R} \$ 0,50,5$ moedas de $\mathrm{R} \$ 0,25,7$ moedas de $\mathrm{R} \$ 0,10,9$ moedas de 0,05 e 10 moedas de 0,$01 ; 2$. a contagem do valor recebido (notas e moedas); 3. escolha por cada sujeito, ainda usando o folheto de supermercado, dos produtos que gostaria de comprar para o lanche na escola e registros do total do seu valor numa folha de papel; 4 . leitura do valor registrado no papel e sua correspondência em notas e moedas; 5. comparação entre o valor inicial $(\mathrm{R} \$ 15,00)$ e o valor do lanche; 6 . retirada do valor do lanche e contagem do dinheiro restante. Assim, todos os sujeitos tinham um mesmo valor de dinheiro para a escolha e a compra do lanche, mas o valor do lanche variava de sujeito para sujeito.

A análise dessa sessão evidenciou que o procedimento comum a todos os alunos foi a formação de conjuntos de moedas e notas de mesmo valor, independente da quantia que formassem juntos. Nessa sessão, ainda se observou dificuldades com a sequência da contagem.

$\mathrm{Na} 6 .^{\mathrm{a}}$ e $7 .^{\mathrm{a}}$ sessões foi retomada a mesma sequência da $5 .^{\mathrm{a}}$, centrando-se agora na notação matemática e incentivando os sujeitos a ir e vir entre a contagem e operações com as notas e as moedas e o seu registro, de modo que o dinheiro servia para checar o registro.

Nessa sessão se evidenciaram mais acertos que erros nos registros das quantias de dinheiro: são diferenciadas a parte inteira e a decimal com o uso correto da vírgula, de modo que podemos já adiantar que o uso do dinheiro como 
suporte para a contagem dos decimais, a sua soma e o registro de quantias de dinheiro, assim como a checagem desse registro se mostrou apropriado.

Seguindo a mesma linha de trabalho, na $8 .^{\text {a }}$ sessão foi proposta uma situação problema na qual foram utilizados os dados obtidos na anterior, acrescida da medida de tempo. Foi desenvolvida a seguinte sequência: inicialmente, foram distribuídos calendários de mesa para cada um dos alunos no grupo e foi então explorado o registro de dias, semanas e meses por meio de questões colocadas ao grupo: Quantos dias vocês vêm para a escola durante a semana? Quantos dias têm a semana? Se por semana vocês vêm 5 dias para a escola, quantos dias vocês não vêm? Quais são esses dias? Que dia acaba o ano letivo? Quando vocês entram de férias? Quantos dias de aula temos até acabar o ano letivo? Há algum feriado neste período? Quantos dias de aula faltam para terminarmos o ano letivo? Se contarmos em semanas, quantas semanas faltam pra terminarmos $o$ ano letivo? $\mathrm{O}$ registro no papel foi incentivado e o grupo chegou a um valor de tempo comum: 18 dias. Em seguida, foi proposta uma situação problema envolvendo a medida monetária e a de tempo: se vocês resolvessem comprar este mesmo lanche (em referência à sessão anterior) todos os dias até o término das aulas, quanto gastariam?

Portanto, o grupo tinha um valor de tempo comum (18 dias) e um valor monetário variável, referente ao valor do lanche escolhido no catálogo de supermercado, por cada um, em sessão anterior: $\mathrm{R} \$ 3,34 ; \mathrm{R} \$ 3,84, \mathrm{R} \$ 3,19 ; \mathrm{R} \$ 2,62$.

$\mathrm{Na} 9{ }^{\text {a }}$ sessão a professora foi tutorada para o desenvolvimento de 3 tipos de atividades envolvendo valores monetários e seu registro: ela anunciava o valor fictício de suas compras no supermercado, como por exemplo: "comprei uma lata de refrigerante que custou R $\$ 0,75$ ”; os alunos eram convidados a pegar de dentro de uma caixa contendo réplicas de notas e moedas o dinheiro referente ao valor anunciado; os alunos comparavam o dinheiro separado e avaliavam se estava certo ou não; uma vez separado o valor corretamente, a professora solicitava aos alunos que o registrasse em reais, numa folha de papel, utilizando a notação matemática.

Nessa sessão, todos os alunos identificaram a parte inteira e os valores dos centavos como sendo a parte de um real (um inteiro). Ou seja: começou a ficar explícito para a professora que a utilização de medidas (monetária e outras) era um procedimento adequado para desenvolver a compreensão da lógica do SND e sua notação, uma vez que a cada sessão o processo de mediação e de interlocução entre os sujeitos resultava em tomadas de consciência que os auxiliava no processo de regulação cognitiva.

$\mathrm{Na} 10$. $^{\mathrm{a}}$ sessão a professora foi tutorada para a utilização da medida de comprimento, inserindo o uso da régua como instrumento de medição. Para cada aluno foram disponibilizados: uma régua de $30 \mathrm{~cm}$, três lápis de tamanhos 
diferentes, quatro livros de tamanhos diferentes, numerados de 1 a 4 . A situação problema consistia no seguinte: cada sujeito deveria medir os três lápis com a régua e fazer a anotação das medidas encontradas; cada sujeito deveria medir cada livro, anotando as medidas de comprimento e de largura encontradas; cada sujeito deveria comparar a sua medida com a medida obtida pela professora, para cada um dos livros. Nessa sessão, os alunos identificaram o milímetro como sendo uma parte do centímetro, separando por vírgula a parte inteira da parte decimal e apresentaram menos dificuldades na identificação do inteiro e dos decimais, assim como de seu registro com a utilização da vírgula.

$\mathrm{Na} 11 .^{\text {a }}$ sessão foi introduzido o relógio como instrumento de medida de tempo, iniciando pela exploração da representação no próprio instrumento, começando pela representação da metade do dia, 12 horas, pela marcação das horas, dos minutos, dos segundos, pela função dos 2 ponteiros e assim por diante. Várias questões foram então colocadas pela Professora (Qual o horário que começa a aula de vocês? Qual é o horário que termina? Quantas horas vocês permanecem na escola? Qual é a hora do recreio? Qual é a duração do recreio? etc.), incentivando os sujeitos a responderem verbalmente e por meio da manipulação do relógio.

A 12. ${ }^{a}$ sessão foi focada na avaliação da intervenção em duas etapas. $\mathrm{Na}$ primeira, todos os alunos foram submetidos individualmente à Prova Conceitual de Resolução de Problemas Numéricos - ECPN (Groupe CIMETE, 1995) já referida. Na segunda etapa lhes foram apresentadas as seguintes situações problemas, uma de cada vez e em uma folha separada, sem a intervenção da professora: a) Ganhei uma caixa de lápis de cor com 6 lápis. Cada um dos lápis mede 6,34 cm e todos têm o mesmo comprimento. Se eu colocar os lápis um atrás do outro em linha reta, qual será o comprimento desta linha? b) Minha mãe me deu $R \$ 10,00$ para eu ir à padaria e comprar um pacote de café que custava $R \$ 3,95$, um pacote de açúcar que custava $R \$ 1,40$ e um pacote de manteiga que custava $R \$ 3,37$. Com quanto de troco eu voltei para casa? c) Neste final de semana, você vai ao cinema assistir ao filme dos robôs. A sessão começa às $15 \mathrm{~h}$ e 15 min e termina às $17 \mathrm{~h}$ e $30 \mathrm{~min}$. Quanto tempo vai durar a sessão de cinema?

A diferença entre o desempenho dos alunos antes e depois das sessões de intervenção, nas provas descritas acima, foi fragrante: todos eles acertaram todas as respostas aos itens da Prova Conceitual de Resolução de Problemas Numéricos - ECPN (Groupe CIMETE, 1995) e todos registraram as operações adequadamente, para a resolução dos problemas, o que difere do início da intervenção, quando o procedimento padrão era o de repetir os algarismos na ordem em que apareciam no enunciado da situação problema. 


\section{Conclusão}

Podemos dizer, assim, que o progresso dos alunos, no que diz respeito às competências relacionadas à lógica do sistema numérico, como evidenciado nas sessões desenvolvidas, se deve à pertinência da articulação, nas atividades mediadas, entre o uso dos instrumentos de medida, a representação da sequência numérica dos instrumentos, a possibilidade de operar com esta sequência e finalmente a notação dessa operação. Esses aspectos levaram os alunos a ter em conta os processos de agrupamento e de decomposição dos valores numéricos, assim como a relação entre a parte e o todo, que operacionalizam o sistema de numeração decimal.

A importância do uso dos instrumentos de medida já havia sido ressaltada por vários autores e, como defendemos, trata-se de um procedimento que, do ponto de vista conceitual do desenvolvimento psicológico, é compatível com os clássicos argumentos de Piaget e Vygotsky no que se refere à descentração e à zona de desenvolvimento proximal: a escolha de situações problemas envolvendo os sistemas de medidas e a utilização de diferentes instrumentos de medida permite fazer comparações de objetos no tempo e à distância, com uma precisão que ultrapassa as nossas habilidades perceptuais (FÁVERO, 2005a).

Vale ainda ressaltar que a mudança de comportamento dos alunos entre as primeiras e as últimas sessões de intervenção atesta uma mudança que podemos considerar relacionada à sua autoestima: no início eles permaneciam calados a maior parte do tempo. No decorrer das sessões a frequência de interlocuções entre eles e entre eles e a professora aumentou e eles passaram a apontar os seus erros e o dos outros e a corrigi-los em voz alta. Do mesmo modo, se evidenciou que no decorrer das sessões a natureza da mediação da professora se modificou: passou a ser menos frequente, dando cada vez mais oportunidade para que os próprios alunos assumissem essa mediação.

Portanto, tanto do ponto de vista do procedimento do tutoramento desenvolvido junto à professora, como do ponto de vista do tutoramento da professora junto aos alunos, podemos dizer que o procedimento adotado foi adequado para o desenvolvimento de novas competências: os dados nos permitiram concluir que três aspectos psicológicos estiveram em pauta: a formação de conceitos e seu sistema lógico de representação, a tomada de consciência desses conceitos e dessa lógica e a interação social que caracteriza a situação didática na qual são construídos. Isso permite a construção de um novo entendimento sobre a avaliação: ela passa a ser vista além de uma aferição das respostas "certas" ou "erradas" do aluno, para ser entendida como uma etapa que alimenta a própria prática didática. 


\section{REFERÊNCIAS}

BAKHTIN, M. Marxismo e filosofia da linguagem. Tradução de: LAHUD, M.; VIEIRA, Y. 6 ed. São Paulo: Hucitec, 1981.

BRASIL. MINISTÉRIO DA EDUCAÇÃO. Lei de Diretrizes e Bases da Educação Nacional, Lei n. 9.394. Brasília-DF, 1996.

BRASIL. MINISTÉRIO DA EDUCAÇÃO/Secretaria de Educação Especial (SEESP). Projeto Escola Viva. Brasília: MEC, 2001a.

. Diretrizes nacionais para a educação especial na educação básica. Resolução

CNE n. 2. Brasília: MEC, 2001b.

. Escola Inclusiva. Brasília: MEC, 2003.

BRUNER, J. Acts of meaning. Cambridge, Massachusetts: Harvard University Press, 1990.

CARPENTER, T. P.; MOSER, J. M. The acquisition of addition and subtraction concepts. In: LESH, R.; LANDAU (Eds.). Acquisition of mathematical concepts and process. New York: Academic Press, 1983. p. 7-44.

EBBY, C. B. Learning to teach mathematics differently: the interaction between coursework and fieldwork for preservice teachers. Journal of Mathematics Teacher Education, v. 3, p. 69-97, 2000.

FÁVERO, M. H. Desenvolvimento cognitivo adulto e a iniciação escolar: a resolução de problemas e a notação das operações. Temas em Psicologia, São Paulo, v. 7, n. 1, p. 79-88, 1999.

. Regulações cognitivas e metacognitivas do professor de primeiro grau: Uma questão para a articulação entre a psicologia do desenvolvimento e a psicologia da educação matemática. In: XXX Reunião da Sociedade Brasileira de Psicologia. Resumos de comunicações científicas. Anais... Brasília-DF: SOCIEDADE BRASILEIRA DE PSICOLOGIA, 2000. p. 11-12.

. Psicologia e conhecimento. Subsídios para a análise do ensinar e aprender. Brasília: EDUnB, 2005a.

. Desenvolvimento psicológico, mediação semiótica e representações sociais: por uma articulação teórica e metodológica. Psicologia: Teoria e Pesquisa, v. 21, n. 1, p. 17-25, 2005b. 
. Paradigme personnel et champ conceptuel: implications pour les situations didactiques. In: MERRI, M. (Org.). Activité Humaine et Conceptualisation. Questions à Gérard Vergnaud. Toulouse: Presses Universitaires du Mirail, 2007. p. 625-634.

. Os fundamentos teóricos e metodológicos da psicologia do conhecimento. In: FÁVERO, M. H.; CUNHA, C. da (Orgs.). Psicologia do Conhecimento. O diálogo entre as ciências e a cidadania. Brasília: Unesco/ Liber Livro, 2009. p. 9-20.

FÁVERO, M. H.; COUTO MACHADO, C. M. A tomada de consciência e a prática de ensino: uma questão para a psicologia escolar. Psicologia: Reflexão \& Crítica, v. 16, n. 1, p. 15-28, 2003.

FÁVERO, M. H.; PIMENTA, M. L. Pensamento e linguagem: a língua de sinais na resolução de problemas. Psicologia: Reflexão \& Crítica, v. 19, n. 2, p. 225-236, 2006.

FÁVERO, M. H.; SOARES, M. T. C. Iniciação escolar e a notação numérica: uma questão para o estudo do desenvolvimento adulto. Psicologia: Teoria e Pesquisa, v. 18, n. 1, p. 43-50, 2002.

FÁVERO, M. H.; VIEIRA, D. O. A construção da lógica do sistema numérico por uma criança com Síndrome de Down. Educar em Revista, n. 23, p. 65-85, 2004.

GEERTZ, C. A interpretação das culturas. Rio de Janeiro: LTD-Livros Técnicos e Científicos Editora, 1989.

GOODELL, J. E. Using critical incident reflections: a self-study as a mathematics teacher educator. Journal of Mathematics Teacher Education, v. 9, p. 221-248, 2006.

GROUPE CIMETE. Compétences et incompétences en arithmétique. Une aide na diagnostic et à l'action pédagogique particullièrement destinée aux entants affectés de difficultés sévères d'apprentissage. Paris: ANAE, 1995. p. 58-63.

KEGAN, R. In over our heads: the mental demands of modern life. Cambridge: Harvard University Press, 1994.

LEE, H. S. Facilitating students' problem solving in a technological context: prospective teacher's learning trajectory. Journal of Mathematics Teacher Education, v. 8, p. 223254, 2005.

LOTMAN, Y. M. Universe of the mind. A semiotic theory of culture. Tradução de: SHUKMAN, A. Bloomington and Indianapolis: Indiana University Press, 1990.

MEAD, G. Mind, Self, and Society. MORRIS, C. W. (Edit.). Chicago: University Chicago Press, 1992. 
MOSCOVICI, S. L'ère des representations sociales. In: DOISE, W.; PALMONARI, A. (Eds.). L'étude des representations sociales. Neuchâtel, Paris: Delachaux et Niestlé, 1986. p. 34-80.

NEVES, R. da S. P.; FÁVERO, M. H. A pesquisa de intervenção no desenvolvimento de competências conceituais: a divisão e os racionais em questão. In: IV SEMINÁRIO INTERNACIONAL DE PESQUISA EM EDUCAÇÃO MATEMÁTICA/SIPEM. Livro de resumos. Brasília-DF: Sociedade Brasileira de Educação Matemática, UCB, 2009. v. 1. p. 1-14. CD-ROM.

PIAGET, J. A tomada de consciência. Tradução de: SOUZA, E. B. São Paulo: Edições Melhoramentos, 1977.

RESNICK, L. B. Syntax and semantics in learning to subtract. In: CARPENTER, T. P.; J. A. MOSER; ROMBERG, T. A. (Eds.). Addition and subtraction: A cognitive perspective. Hillsdale, N. J: Lawrence Erlbaum Associates, 1982.

SINNOTT, J. D. The development of logic in adulthood: postformal thought and its applications. New York: Plenum Press, 1998.

SOUZA, C. M. S. G.; FÁVERO, M. H. Análise de uma situação de resolução de problemas de física, em situação de interlocução entre um especialista e um novato, à luz da teoria dos campos conceituais de Vergnaud. Investigações em Ensino de Ciências, v. 7, n. 1, p. 55-75, 2002.

VERGNAUD, G. La théorie des champs conceptuels. Recherches en didactique des mathématiques, v. 10, n. 23, p. 133-170, 1990.

VYGOTSKY, L. S. Consciousness as a Problem in the Psychology of Behavior. Soviet Psychology, v. XVII, n. 4, p. 35, 1979.

WALLON, H. Psychologie et matérialisme dialectique. Enfance, Numero special "Henri Wallon, buts et méthodes de la psychologie”, p. 31-34, Janvier-Avril 1963.

YOUNG, G. Adult development, therapy and culture: A post-modern synthesis. New York: Plenum Press, 1997. 